\title{
DISTRIBUIÇÃO DE ELEMENTOS LEVES DENTRO DO VP EM PORTUGUÊS: interação entre sintaxe, prosódia e estrutura informacional em teoria da otimidade ${ }^{1}$
}

\author{
THE DISTRIBUTION OF LIGHT CONSTITUENTS INSIDE VP IN PORTUGUESE: \\ The Interaction between Syntax, Prosody and Information Structure \\ in Optimality Theory
}

\author{
Gabriel de Ávila Othero \\ Universidade Federal do Rio Grande do Sul $\backslash \mathrm{CNPq}$ \\ Sérgio de Moura Menuzzi \\ Universidade Federal do Rio Grande do Sul $\backslash \mathrm{CNPq}$
}

\begin{abstract}
Resumo
Neste artigo, analisamos o fenômeno da ordem de palavras dentro do VP em português, especialmente na variação entre complemento e advérbios monossilábicos, utilizando, para isso, o modelo da Teoria da Otimidade (TO). Mostramos que o modelo proposto pela TO permite colocar em pé de igualdade restrições de natureza sintática, prosódica e de estrutura informacional da frase que atuam sobre a distribuição dos elementos dentro do VP em português. Partimos da análise de Costa (1998) para a distribuição do acento nuclear da frase e de sua proposta para explicar o acento em advérbios monossilábicos dentro do VP e propomos quatro restrições (duas relativas à estrutura informacional da frase e duas de natureza prosódica) que podem explicar, de maneira econômica e relativamente bem motivada, a distribuição do acento nuclear da frase quando temos elementos leves dentro do VP em português.
\end{abstract}

Palavras-chave: Ordem de palavras. Foco. Estrutura Informacional da Frase. Teoria da Otimidade.

\begin{abstract}
In this article, we analyze the word order variation inside the VP in Portuguese, namely the distribution of complements and light adverbs inside the VP. We begin by presenting Costa's (1998) analysis of the order of monosyllabic adverbs in Portuguese and its relation to the primary stress of the clause. Optimality Theory allows us to represent different kinds of grammatical constraints to be computed in a parallel fashion such that there is no need for a syntactocentric approach. We propose four interface constraints that can explain the phenomena of word order variation inside the VP in Portuguese (two constraints are prosodically motivated and two are related to information structure phenomena).
\end{abstract}

Keywords: Word order. Focus. Information Structure. Optimality Theory.

\footnotetext{
1 Agradecemos a leitura atenta e os comentários pertinentes feitos pelos colegas Maria Cristina Figueiredo Silva e Flávio Martins de Araújo. O presente trabalho é parte do projeto "Estrutura sintagmática em Teoria da Otimidade: interação de condições gramaticais na organização da sentença em português", processo n. 505331/2008-0 do CNPq.
} 


\section{INTRODUÇÃO}

A Teoria da Otimidade (TO) é uma teoria recente de base gerativa que difere substancialmente da tradição gerativa derivacional por enfatizar o caráter representacional das restrições gramaticais (cf. Prince e Smolensky, 1993; McCarthy e Prince, 1993). Uma das grandes inovações da TO é que ela é essencialmente uma formalização da ideia de gramática como instrumento de resolução de conflitos entre princípios gramaticais. Essa concepção requer que as condições gramaticais sejam avaliadas simultaneamente, em paralelo - sem isso, não há conflito entre condições. Uma consequência natural da teoria é que não é necessário conceber a relação entre os diferentes componentes da gramática - léxico, morfologia, sintaxe, semântica, prosódia - como sendo linear ou sequencial ou, ainda, de input-output; essa relação pode ser simplesmente paralela, com atuação simultânea de diferentes componentes sobre as mesmas representações. É em virtude dessa atuação simultânea que as condições de diferentes componentes da gramática podem entrar em conflito entre si.

Como discutiremos neste artigo, a abordagem otimalista permite rever questões que tradicionalmente eram concebidas como exclusivamente sintáticas. Em particular, ela nos permitirá revisitar questões relativas à estrutura sintagmática da sentença e à ordem dos elementos dentro do sintagma verbal (VP) em português. Acreditamos que alguns dos problemas tradicionais da análise sintagmática podem ser vistos como resultados da interação entre condições sintáticas propriamente ditas - como as que são codificadas pela teoria X-barra - e condições de outros componentes gramaticais - condições semânticas, prosódicas, pragmáticas e de estrutura informacional, por exemplo.

Grande parte do trabalho em TO tem sido desenvolvido nas áreas de Morfologia e Fonologia, e, nessas áreas, já encontramos vários trabalhos interessantes sobre $\mathrm{o}$ português brasileiro (PB) (cf., entre outros, Abaurre et al., 2001; Bonilha, 2001, 2007; Bisol e Magalhães, 2005; Abaurre e Sandalo, 2007; Lee, 2007; Schwindt, 2007). Estudos em sintaxe baseada em TO, por outro lado, demoraram a se difundir; somente por volta do final da década de 1990 é que se tornaram uma alternativa reconhecida às abordagens derivacionais (ver, por exemplo, Barbosa et al., 1998; Legendre, Grimshaw e Vikner, 2001; Sells, 2001). Os primeiros trabalhos em TO sobre a sintaxe do português de que temos notícias foram os de Costa (1998) e Menuzzi (1999). Contudo, ao contrário do que aconteceu em Fonologia e Morfologia, esse impulso inicial não obteve grande repercussão: há, hoje, poucos pesquisadores tentando aplicar uma abordagem em TO ao estudo da sintaxe do português de modo sistemático, especialmente no Brasil.

Neste artigo, pretendemos mostrar que algumas explicações concebidas como exclusivamente sintáticas merecem ser revistas se levarmos em consideração que não há necessidade de os fatores sintáticos terem primazia sobre outros componentes da gramática que estejam atuando na organização dos constituintes na frase. Mostraremos que o modelo proposto pela TO permite colocar em pé de igualdade restrições de natureza sintática, prosódica e de estrutura informacional da frase que parecem estar atuando sobre a distribuição dos elementos dentro do VP em português.

O artigo está organizado como segue: na seção 2, apresentaremos uma síntese da análise de Costa (1998) para a distribuição do acento nuclear da frase e sua proposta para 
explicar o acento em advérbios monossilábicos dentro do VP, apontando para o fato de que sua análise exige uma estrutura sintática abstrata precisamente porque vê a atribuição de acento como estritamente dependente da sintaxe. Na seção 3, apresentaremos a arquitetura básica da TO e algumas de suas ideias centrais, entre as quais enfatizaremos a ideia de que condições sintáticas, prosódicas etc. podem ser formuladas de modo autônomo e, ainda assim, podem atuar simultaneamente sobre as representações gramaticais da frase. $\mathrm{Na}$ seção 4, iremos propor quatro restrições (duas relativas à estrutura informacional da frase e duas de natureza prosódica) que podem explicar, de maneira econômica e relativamente bem motivada, a distribuição do acento nuclear da frase quando temos elementos leves dentro do VP em PB. Na seção 5, faremos algumas considerações finais sobre as ideias que apresentamos aqui.

\section{A DISTRIBUIÇÃO DE ACENTO E A ORDEM DOS ADVÉRBIOS MONOSSILÁBICOS DENTRO DO VP - A ANÁLISE DE COSTA (1998)}

Costa (1998) propôs, para a sintaxe da ordem dos constituintes pós-verbais em português europeu (PE), uma análise baseada na teoria de Cinque (1993) sobre a relação entre estruturação sintagmática e a distribuição do acento nuclear na frase ${ }^{2}$. De acordo com essa teoria, o elemento que deve receber o acento nuclear é o constituinte mais encaixado na estrutura sintagmática da frase. No caso da ordem Verbo - Advérbio Complemento, como em (1), em que o acento nuclear recai sobre o complemento, teríamos a estrutura sintagmática apresentada em (2):

(1) Que língua o João fala bem? O João fala bem INGLÊS ${ }^{3}$.

(2)

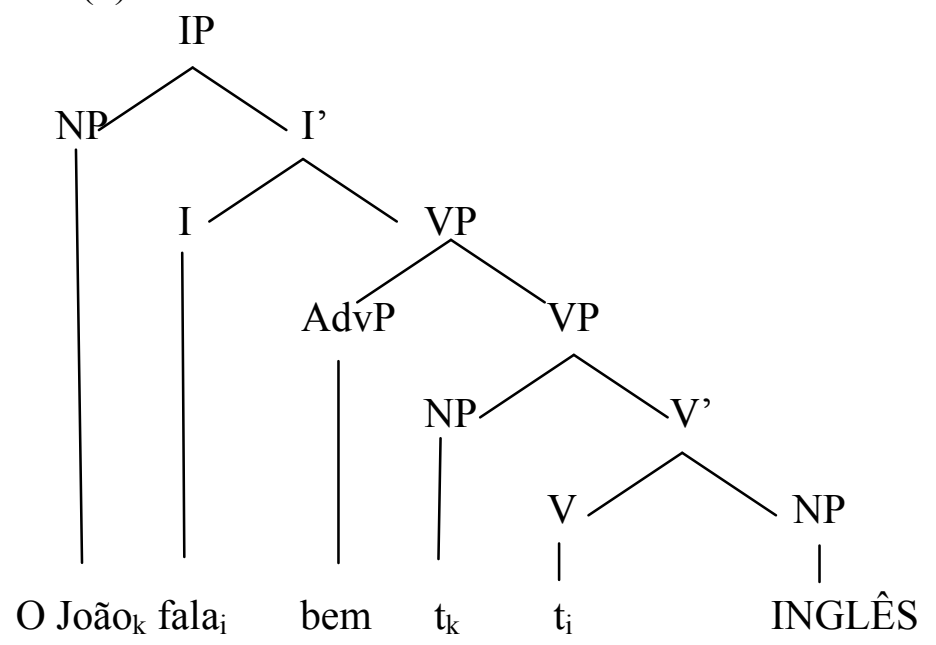

Na representação em (2), o sintagma nominal (NP) sujeito e o verbo foram movidos de suas posições de base, enquanto o advérbio e o NP complemento permanecem em sua posição de base; o complemento é o constituinte mais encaixado da estrutura e,

\footnotetext{
${ }^{2} \mathrm{O}$ que segue é parcialmente baseado na discussão que Menuzzi e Mioto (2006) fazem da proposta de Costa (1998).

${ }^{3}$ As maiúsculas marcam o constituinte sobre o qual recai o acento nuclear da frase.
} 
portanto, de acordo com Cinque - e Costa - deve receber o acento nuclear da frase: "João fala bem INGLÊS".

No entanto, quando analisamos a ordem Verbo - Complemento - Advérbio, em que o acento nuclear recai sobre o advérbio, como em (3) abaixo, a representação sintagmática tradicional - como em (4), com o advérbio pendendo à direita do VP - se torna problemática:
(3) Como o João fala inglês?
O João fala inglês BEM.

Na representação em (4), o elemento mais encaixado da estrutura é o NP complemento e não o advérbio. Portanto, seguindo Costa e Cinque, o acento não poderia recair sobre o adjunto, como efetivamente acontece; deveria recair sobre o complemento, que é o elemento mais encaixado.

(4)

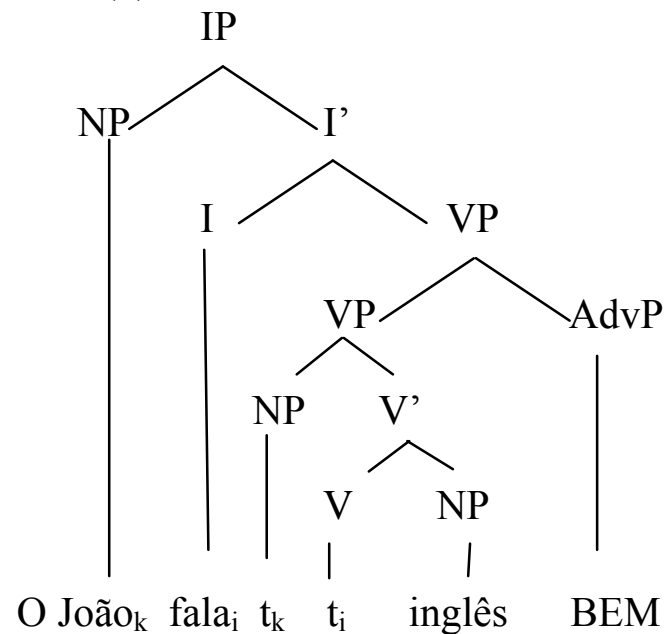

Especialmente por esse motivo, Costa (1998) propõe que a ordem Verbo Complemento - ADVÉRBIO seja derivada por scrambling em português ${ }^{4}$; ou seja, ele propõe que essa ordem seja derivada pelo movimento do complemento para a esquerda. Esse movimento é de adjunção a VP, resultando na estrutura em (5):

\footnotetext{
${ }^{4}$ Cinque recorre a uma estratégia diferente: para ele, os advérbios são gerados na posição de complementos em estrutura com "VP shells", isto é, [vp NP [ $v^{\prime} \mathrm{V}\left[\mathrm{vP}\right.$ NP [ $\mathrm{v}^{\prime} \mathrm{t}$ AdvP ]]].
} 
(5)

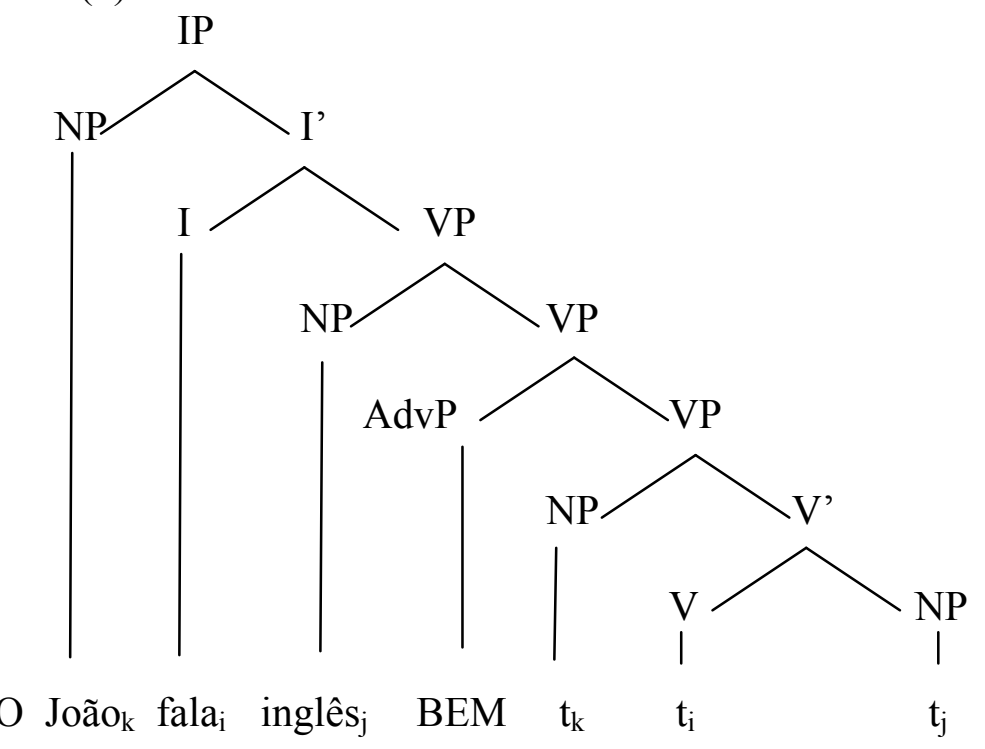

Dessa forma, o constituinte mais encaixado na estrutura sintagmática passa a ser o advérbio. Sendo o constituinte mais encaixado, o advérbio recebe, de acordo com a teoria de Cinque, acento nuclear da frase: "João fala inglês BEM".

Esse tipo de análise, baseado na proposta de Cinque (1993), apresenta, no entanto, um problema conceitual claro: por adotar a hipótese de que a atribuição do acento nuclear é diretamente dependente da estrutura sintagmática da frase, a análise exige que a estrutura seja organizada de modo que o acento sempre corresponda ao constituinte mais encaixado; por isso, de acordo com Costa (1998), o movimento de scrambling dos complementos é prosodicamente motivado em português: é graças à operação de scrambling que o complemento deixa de ser o constituinte mais encaixado e que o advérbio passa a ocupar a posição adequada para receber o acento nuclear.

No entanto, acreditamos que esse modo de conceber a relação entre sintaxe e prosódia não é necessário. A estrutura prosódica possui autonomia relativa com relação à sintaxe e, a nosso ver, pode inclusive superá-la na determinação da ordem dos constituintes (cf. Harford e Demuth, 1999; Keller e Alexopoulou, 2001; Büring, 2005; Samek-Lodovici, 2005, entre muitos outros); por isso acreditamos que postular uma estrutura sintagmática abstrata e uma derivação sintática (o movimento por scrambling) para obedecer ao princípio proposto por Cinque (1993) para o acento nuclear coloca problemas conceituais acerca da interação entre sintaxe e fonologia. De fato, muitos fonólogos argumentam que não há correspondência direta entre sintagmas sintáticos e sintagmas fonológicos e que a atribuição de acentos da frase não depende diretamente das fronteiras de sintagmas sintáticos, mas da segmentação da frase em sintagmas fonológicos (cf. Nespor e Vogel, 1986; Sandalo e Truckendbrodt, 2003; Bisol, 2005, entre outros). Assim, a nosso ver, uma análise da focalização de adjuntos por meio de uma derivação com scrambling em português não incorpora assunções correntes acerca da interface entre sintaxe e prosódia - em particular, não faz jus à autonomia da 
prosódia em relação à sintaxe - e, por isso, tem um custo teórico alto; só pode ser justificada com base em evidência empírica inequívoca ${ }^{5}$.

Não é nenhuma novidade observar que os padrões de ordem dos constituintes do VP têm sido atribuídos a diferentes tipos de fatores e processos. Há análises que, ainda que reconhecendo algum papel para a prosódia, têm um cunho altamente "sintaticizante", como é o caso da abordagem de Costa (1998) que estamos discutindo (e também Miyagawa, 1997, entre outros). Há outras que se baseiam fundamentalmente em distinções relativas à articulação informacional da frase e praticamente desconhecem qualquer papel independente para a estrutura sintagmática (como em abordagens funcionalistas que adotam alguma das diferentes versões do "princípio do dinamismo comunicativo"; cf. Givón, 1989, entre outros). Há quem tenha proposto que operações como scrambling em línguas germânicas estejam associadas basicamente à distinção semântica entre DPs específicos e não-específicos (cf. de Hoop, 1992). E há, é claro, análises em que se sugere um papel fundamental, central, para as condições de prosódia (cf. Selkirk, 1995; Menuzzi e Mioto, 2006, entre muitos outros).

Como já afirmamos, acreditamos que o fenômeno envolva restrições de diferentes componentes gramaticais interagindo de diferentes modos em diferentes línguas. Essa ideia, evidentemente, nada tem de novidade - ela tem sido explorada com particular interesse em vários estudos da variação de ordem baseados na abordagem TO (o que inclui, inclusive, a segunda parte da tese de Costa, 1998; além de Choi, 1997 e 1999, entre outros). No caso específico da ordem dos advérbios monossilábicos que recebem o acento nuclear da frase em português, parece haver, pelo menos, quatro restrições (que apresentaremos na seção 4) em jogo: duas relativas à estrutura informacional e duas de natureza prosódica; não estamos certos de que haja algum papel pertinente para condições sintagmáticas independentes - e, concomitantemente, precisaremos de "pouca sintaxe" para lidar com o fenômeno da distribuição dos advérbios monossilábicos no interior do VP. Essa é, talvez, a principal novidade da linha de análise que proporemos a seguir.

$\mathrm{Na}$ verdade, uma abordagem com papel mínimo ou nenhum para as condições de estrutura sintagmática não deveria ser uma surpresa: numa abordagem TO da sintaxe, é possível conceber - e fácil de formalizar - gramáticas em que o papel das condições sintáticas na determinação da ordem é relativamente pequeno, por oposição ao papel das condições impostas por outros componentes da gramática, como a prosódia e a estrutura informacional da frase. Na prática, entretanto, as análises baseadas em TO têm preservado muito da estrutura sintagmática abstrata necessária a operações como o "movimento por adjunção" de constituintes (ver, por exemplo, Samek-Lodovici, 2005).

Nosso intuito aqui será mostrar a plausibilidade de uma análise da ordem dos constituintes do VP em que a estrutura sintagmática pode ser simplificada significativamente - possivelmente, para os casos que discutiremos abaixo, a estrutura sintagmática pode ser reduzida a um modelo de representação semelhante ao proposto

\footnotetext{
5 Quanto a isso, ver Menuzzi e Mioto (2006), que fazem uma crítica detalhada à proposta de Costa (1998). Para uma contribuição empírica importante para o debate entre Costa (1998) e Menuzzi e Mioto (2006), ver Figueiredo Silva e Araújo (2008). Retomaremos a alguns pontos desses trabalhos na discussão que segue.
} 
por Culicover e Jackendoff (2005): não mais que a ideia de "sintagma verbal", ou de "agrupamento do verbo com seus complementos e adjuntos", parece ser necessária; nos casos que estudaremos, a ordem de complementos e adjuntos no interior do VP segue da interação das condições prosódicas e da articulação informacional.

Em resumo, pretendemos argumentar neste artigo que a ordem dos constituintes do VP em português brasileiro - ao menos, naquilo que diz respeito, especificamente, à distribuição de advérbios monossilábicos - é resultado, na verdade, não de condições estritamente sintagmáticas, mas antes da interação entre prosódia e articulação informacional. E pretendemos, ainda, mostrar que essa análise pode ser expressa adequadamente numa abordagem TO da sintaxe, em que há conflito entre condições de diferentes componentes gramaticais porque estes operam simultaneamente sobre as representações linguísticas ${ }^{6}$.

\section{TEORIA DA OTIMIDADE - SÍNTESE}

A Teoria da Otimidade é um modelo linguístico que se iniciou com os trabalhos de McCarhty e Prince (1993) e Prince e Smolensky (1993). Sua arquitetura básica conta com um input, que correspondente, grosso modo, à "representação subjacente" de uma expressão E - uma palavra ou uma sentença, por exemplo; um Gen(erator), função responsável por criar, a partir do input, um conjunto de "candidatos a output", isto é, de "representações superficiais" correspondentes a modos alternativos de realizar E; e um Eval(luator), função responsável por avaliar o conjunto de "candidatos a output" e decidir, entre eles, qual é a "melhor forma para E".

Em sintaxe TO, as análises comumente assumem que o input contém uma representação do "conteúdo proposicional" de uma sentença - isto é, informação especificando os predicadores da frase, seus argumentos etc. - bem como alguma informação de natureza pragmática, como a função discursiva dos diferentes elementos do conteúdo proposicional (por exemplo, que argumento é o "tópico" da frase; qual o "foco" da frase etc.). ${ }^{7}$ Já os "candidatos a output" são normalmente concebidos como formas alternativas de realizar a "estrutura-S" da sentença - isto é, a estrutura sintática da frase já com a possibilidade de realizar relações gramaticais típicas da superfície (deslocamento de constituintes, atribuição de Caso estrutural, co-indexação relativa às relações de anáfora etc.).

Eval é o mecanismo que irá selecionar o melhor candidato entre todos os candidatos gerados por Gen, através da avaliação de cada candidato de acordo com um conjunto de restrições violáveis e universais que são ranqueáveis na gramática particular da língua. $\mathrm{O}$ candidato que incorrer em menos violações a essas restrições, ou que violar restrições mais baixas na hierarquia da língua, será escolhido como o candidato ótimo ou gramatical. As restrições são condições universais que regem diferentes aspectos da boa formação das expressões. Elas atuam de forma paralela e podem, portanto, ser de

\footnotetext{
${ }^{6}$ De nosso conhecimento, não há estudos da ordem dos constituintes em PB no quadro da TO; para o português europeu, há a série de trabalhos publicados por João Costa (COSTA, 1996a, b, c, 1998, 2001b, c); para o inglês e algumas outras línguas, encontramos Grimshaw (1997), Choi (1997, 1999), Sells (2001), Fukaya (2002), Bury (2003), Engels (2004), entre outros.

${ }^{7}$ Cf. Bresnan (1996), Grimshaw (1997) e Kuhn (2003), por exemplo.
} 
componentes gramaticais distintos, o que permite que entrem em conflito. Uma restrição pode ser violada desde que essa violação seja necessária para que outra restrição conflitante mais alta na hierarquia da língua seja satisfeita. As análises em TO que utilizam restrições de diferentes componentes da gramática (como restrições sintáticas, prosódicas, de estrutura informacional etc.) têm sido chamadas particularmente de SPOT, Strong Parallel Optimality Theory. Em análises desse tipo, não há um componente gramatical que seja mais central do que outros; as restrições são avaliadas de maneira paralela e simultânea e são ranqueáveis - a diferença no ranking das restrições irá resultar na gramática de diferentes línguas ${ }^{8}$.

Abaixo vemos um modelo esquemático da arquitetura básica da $\mathrm{TO}^{9}$.

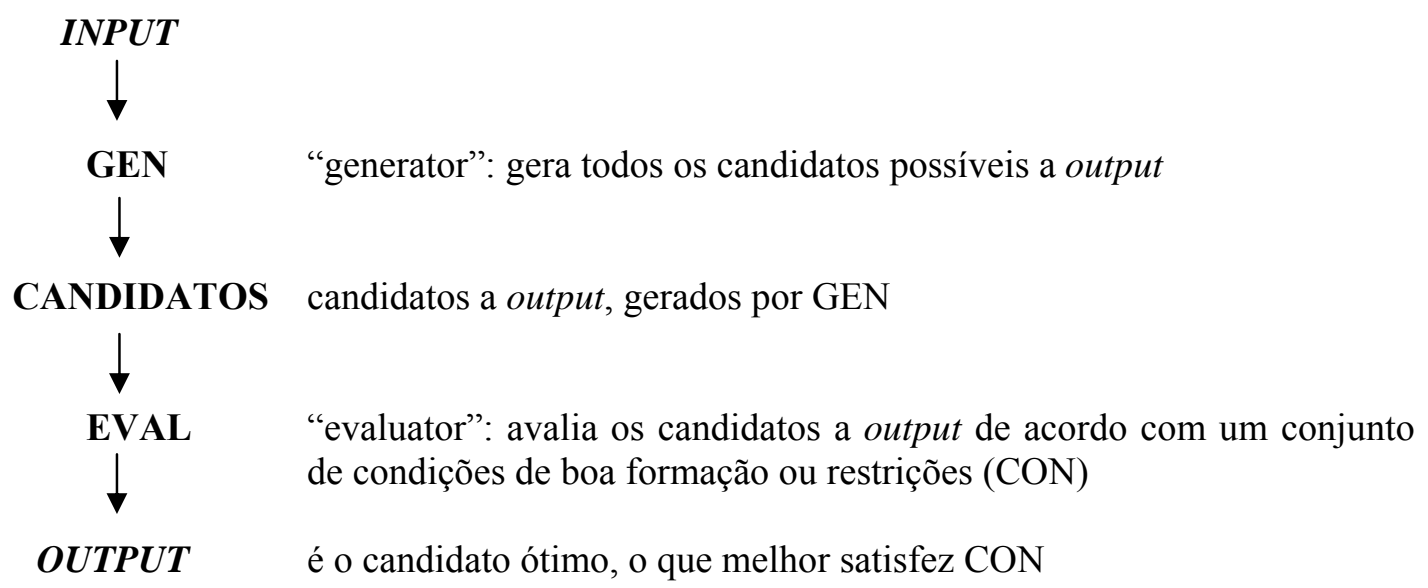

Suponhamos, por exemplo, que a gramática da língua $\mathrm{L}$ apresente um conjunto de princípios universais, tais como $\mathrm{C}_{1}, \mathrm{C}_{2}$ e $\mathrm{C}_{3}$, que atuam sobre determinado fenômeno. $\mathrm{A}$ gramática da língua $\mathrm{L}$ organiza essas condições de acordo com a seguinte hierarquia: $\mathrm{C}_{1}$ $>\mathrm{C}_{2}>\mathrm{C}_{3}$.

Suponhamos que existam três candidatos a output: A, B e C. Podemos avaliá-los utilizando o seguinte tableau:

\begin{tabular}{|c|c|c|c|}
\hline Candidatos & $\mathbf{C}_{1}$ & $\mathbf{C}_{2}$ & $\mathbf{C}_{3}$ \\
\hline $\mathbf{A}$ & $* !$ & & $*$ \\
\hline $\mathbf{B}$ & & $* !$ & $*$ \\
\hline $\mathbf{C}$ & & & \\
\hline
\end{tabular}

TABLEAU $1^{10}$

\footnotetext{
${ }^{8}$ Pelo nosso conhecimento, o termo SPOT, Strong Parallel Optimality Theory, foi cunhado por Teeple (2008), ainda que trabalhos anteriores em TO já tivessem apresentado análises em que restrições de diferentes componentes da gramática estivessem atuando de maneira paralela sobre os fenômenos da língua, como Golston (2005) e Samek-Lodovici (2005).

${ }^{9}$ Adaptado de McCarthy (2002, p. 10).

${ }^{10} \mathrm{O}$ tableau deve ser lido como segue: as restrições $\mathrm{C}_{1}, \mathrm{C}_{2}$ e $\mathrm{C}_{3}$ estão apresentadas de maneira hierárquica, obedecendo ao ranking $\mathrm{C}_{1} \gg \mathrm{C}_{2} \gg \mathrm{C}_{3}$. $\mathrm{O}$ sinal aponta o candidato ótimo, aquele que melhor satisfez CON e que será gerado como output. $\mathrm{O}$ asterisco significa uma violação a uma condição; o ponto de exclamação marca uma violação fatal. Para uma introdução à TO, cf. Archangeli (1997), Costa
} 
Para a língua $\mathrm{L}$ em questão, na análise acima, o candidato ótimo será $\mathrm{C}$, pois ele viola apenas a restrição gramatical mais baixa na hierarquia da língua. Ainda que ele tenha violado uma das condições $\left(\mathrm{C}_{3}\right)$, ele satisfez duas outras restrições mais importantes na hierarquia $\left(\mathrm{C}_{1}\right.$ e $\left.\mathrm{C}_{2}\right)$. Os demais candidatos violaram condições mais altas na hierarquia $\mathrm{e}$, por isso, foram descartados: o candidato $\mathrm{A}$ violou apenas uma restrição, mas foi a restrição mais alta na hierarquia $\left(C_{1}\right)$; o candidato $B$ violou duas restrições $\left(C_{2}\right.$ e $\left.C_{3}\right)$. As duas ideias centrais da TO são, portanto, (i) que as condições gramaticais são violáveis e ranqueáveis; e (ii) que os candidatos ótimos não precisam necessariamente satisfazer todas as restrições gramaticais.

Na próxima seção, iremos propor uma análise em TO como alternativa à análise de Costa (1998) para a distribuição dos advérbios monossilábicos dentro do VP. Mostraremos como quatro restrições parecem estar atuando sobre o fenômeno; duas restrições são de natureza prosódica e duas de estrutura informacional da frase.

\section{RESTRIÇÕES ATUANTES NA DISTRIBUIÇÃO DE ELEMENTOS LEVES DENTRO DO VP}

Como mencionamos na seção 1, acreditamos que a distribuição dos elementos dentro da frase em português esteja obedecendo a exigências de diferentes componentes gramaticais. Para dar conta da análise da distribuição de elementos leves dentro do VP, por exemplo, propomos aqui quatro restrições, duas envolvendo a estrutura informacional da frase (a relação entre a função de foco e a posição do constituinte; e entre a função de foco e o acento nuclear da frase) e duas restrições de natureza prosódica (que dizem respeito à complexidade dos sintagmas fonológicos).

\subsection{Restrições de estrutura informacional}

Vejamos as frases (6) e (7), que apresentam variação da posição do advérbio monossilábico dentro do $\mathrm{VP}^{11}$ :

(6) A: Que língua o João fala bem?

B: a) O João fala bem INGLÊS.

b) ? O João fala INGLÊS bem ${ }^{12}$.

c) \# O João fala BEM inglês.

d) \# O João fala inglês BEM.

(7) A: O João morou na Austrália por dois anos.

B: $\quad$ Como é que ele fala inglês?

A: $\quad$ a) \# Ele fala bem INGLÊS.

(2001a), McCarthy (2002), Schwindt (2005) entre outros. Para uma introdução informal à TO, cf. Dresher (1996) e Othero (2008).

${ }^{11}$ Embora Costa (1998), Menuzzi e Mioto (2006) e Figueiredo Silva e Araújo (2008) dediquem-se a discutir a ordem dos advérbios monossilábicos dentro do VP em português, nenhum desses estudos propôs uma análise otimalista do fenômeno, que é o que fazemos aqui.

$12 \mathrm{O}$ ponto de interrogação (?) indica que a frase não é a mais natural, mas é aceitável, no contexto; os dois pontos de interrogação (??) marcam uma frase pouco natural, talvez inaceitável, no contexto; o sinal \# marca uma frase inaceitável no contexto. 
b) \# Ele fala INGLÊS bem.

c) Ele fala BEM inglês.

d) Ele fala inglês BEM. ${ }^{13}$

A ordem do advérbio "bem" dentro do VP varia de acordo com o contexto em que a frase ocorre: em (6), a melhor frase é (6a), em que há a ordem Verbo - Advérbio Complemento, e o acento recai sobre o complemento, que está em posição final e é foco informacional da frase. No outro extremo, as piores frases são (6c) e (6d), em que o acento recai sobre o advérbio, que não é o foco informacional.

Em (7), há situação inversa: a melhor resposta à pergunta em questão parece ser (7d), que apresenta a ordem Verbo - Complemento - Advérbio (ainda que (7c) também seja aceitável, cf. nota 15). Em (7d), o acento recai sobre o foco informacional - o advérbio -, que está ocupando a posição final. No outro extremo, a frase menos aceitável é (7a), que tem a ordem Verbo - Advérbio - Complemento, com o acento recaindo sobre o complemento, que não é foco informacional, mas ocupa a posição final da frase.

Parece que estamos frente a um caso em que fatores de diferentes componentes da gramática estão fazendo exigências distintas com relação à organização interna do VP. Em primeiro lugar, o contraste entre as frases mais aceitáveis e menos aceitáveis de (6) e (7) revela o bem conhecido fato de que o acento nuclear da frase deve recair sobre o constituinte que é foco informacional - o NP complemento ("inglês") em (6) e o adjunto ("bem”) em (7). Além disso, também é bem sabido que, em línguas como o português, o constituinte focalizado deve, preferencialmente, ocupar a posição final na frase. Para expressar esses fatos, propusemos estas duas restrições:

(8) ACENTUEFoco: o foco informacional deve ser marcado pelo acento mais proeminente da sentença ${ }^{14}$.

(9) AlinheFoco: um constituinte que é foco informacional deve ocupar a posição mais à direita da frase ${ }^{15}$.

\footnotetext{
${ }^{13}$ Consultamos alguns falantes nativos do PB sobre o julgamento de aceitabilidade dessas frases. Para alguns, (7c) parece levemente melhor que (7d) no contexto; para outros, o julgamento é o inverso. No experimento de Figueiredo Silva e Araújo (2008, p. 20), contudo, frases como (7d) foram mais aceitas do que frases como (7c): "a ordem V-Compl-AdvMA [advérbio monossilábico átono, como "bem"] é majoritária, sendo escolhida em 27 das 42 possibilidades de ocorrência [no experimento apresentado por esses autores]. É certo que há uma tendência geral de escolha que se conforma grosso modo com o que prevê Costa (1998): o advMA aparece com alguma frequência em posição final quando a sentença é resposta para uma pergunta exatamente sobre ele, e mesmo [que] sua presença em posição final também seja ligeiramente majoritária quando em respostas para questões sobre o objeto, temos aqui também na maior parte das ocorrências a mudança de tessitura sobre o advérbio, o que pode ser indicativo do fato de que ele não faz parte da sentença para a qual o acento sentencial está sendo atribuído".

${ }_{14}$ Restrição baseada em Jackendoff (1972), Selkirk (1984), Erteschik-Shir e Lappin (1993), Reinhart (2003), Truckenbrodt (2005), Erteschik-Shir (2007).

${ }^{15}$ Restrição baseada em Grimshaw e Samek-Lodovici (1995, 1998), Costa (2001b), entre outros. Para uma primeira aproximação, a presente formulação nos parece suficiente. No entanto, acreditamos que essa condição é, na verdade, efeito conjunto de duas condições diferentes: a informacional propriamente dita, que simplesmente exige que foco tenha o acento mais proeminente da frase (cf. Selkirk, 1984, entre outros), e outra prosódica, segundo a qual o "acento nuclear" da frase, isto é, aquele atribuído pela regra
} 
A restrição em (8) é uma restrição de interface entre marcação acentual e a função de foco informacional; a restrição (9) diz respeito à posição que um constituinte focalizado ocupa na frase. Essas restrições apontam corretamente para o fato de que as frases (6a) e (7d) são as mais aceitáveis justamente porque marcam o constituinte focalizado com o acento nuclear da frase e o apresentam na posição final (ver, no entanto, as observações na nota 13$)$.

$\mathrm{Na}$ verdade, a associação entre foco e acento, ou algum outro tipo de realce prosódico ou entoacional, parece ser um princípio universal nas línguas (cf. referências da nota $14)^{16}$. Afinal, esse é um princípio que desempenha um papel importante nas duas vias do processo de codificação e decodificação dos enunciados na comunicação: por um lado, é importante para o falante marcar o constituinte focalizado (a informação nova) com um acento proeminente, de realce; por outro lado, é importante para o ouvinte reconhecer, na fala de seu interlocutor, o foco informacional - marcado pelo acento mais proeminente - na mensagem que está sendo decodificada.

Com base nessas duas condições, já podemos analisar as frases em (6) e (7), através dos seguintes tableaux:

\begin{tabular}{|l|c|c|}
\hline & ACENTUEFOCO & ALINHEFOCO \\
\hline a. Ele fala bem INGLÊS & & $* !$ \\
\hline b. Ele fala INGLÊS bem & $* !$ & $*$ \\
\hline c. Ele fala BEM inglês & $* !$ & $*$ Ele fala inglês BEM \\
\hline
\end{tabular}

TABLEAU 2. Análise das frases em (6): Resposta a “Que língua o João fala bem?” - Foco no complemento

\begin{tabular}{|l|c|c|}
\hline & ACENTUEFOCO & ALINHEFOCO \\
\hline a. Ele fala bem INGLÊS & $* !$ & $*$ \\
\hline b. Ele fala INGLÊS bem & $* !$ & $* !$ \\
\hline c. Ele fala BEM inglês & & \\
\hline d. Ele fala inglês BEM & & \\
\hline
\end{tabular}

TABLEAU 3. Análise das frases em (7): Resposta a "Como é que o João fala inglês?" - Foco no adjunto

Mostramos, nos tableaux 2 e 3, a análise da relação entre a posição do advérbio monossilábico dentro do VP e a distribuição de acento. O ranqueamento do português em relação às restrições AlinheFoco e ACENTUEFoco é o seguinte:

(10) ACENTUeFoco $>>$ ALINHEFoco

default de acento frasal, recai sobre o último sintagma prosódico da frase (cf. Nespor e Vogel 1985, entre outros). Pretendemos desenvolver essa ideia em outros trabalhos.

${ }^{16}$ Por "princípio universal", entendemos um "princípio inviolável” nas línguas: desconhecemos línguas que não marquem o constituinte focalizado com o acento nuclear da frase. Contudo, se for realmente o caso de (8) ser um princípio inviolável, então não poderemos ranqueá-lo da mesma maneira que as outras restrições gramaticais (violáveis em sua natureza) que propusemos. Mantivemos a restrição tal como está; alguns autores sustentam que há línguas que não utilizam acentos para marcar constituintes focalizados (hixkaryana, cf. Derbyshire 1985; nlaka'pamux, cf. Koch, 2008; alguns crioulos, cf. Byrne e Winford 1993). Além disso, alguns autores sustentam que o realce de acento é uma estratégia necessária, mas não suficiente, para a marcação de constituintes focalizados (cf. Kiss, 1995; Choi, 1997, 1999; Frota, 2000). 
Os candidatos ótimos nos dois tableaux são os candidatos que não violam nenhuma das duas restrições. Os candidatos menos aceitáveis violam as duas restrições.

\subsection{Duas restrições de natureza prosódica}

Lidar com a distribuição dos advérbios monossilábicos dentro do VP requer ainda mais estudo. Parece que as duas restrições que propusemos na seção anterior dão conta de VPs com elementos leves, como os advérbios monossilábicos, que aparecem depois de um complemento NP, como vimos nos exemplos até aqui. No entanto, nosso julgamento muda quando o complemento do verbo é um elemento mais "pesado", como um sintagma preposicional (PP) ou um NP complexo:

(11) O João andava meio doente. Como é que ele saiu da aula ontem?

a. Ontem o João saiu BEM da aula.

b. ? Ontem o João saiu da aula BEM. ${ }^{17}$

c. \# Ontem o João saiu DA AULA bem.

d. \# Ontem o João saiu bem DA AULA.

(12) A: O João aprendeu inglês lendo Shakespeare.

B: $\quad$ E como ele fala inglês shakesperiano?

A: a. Ele fala BEM o inglês shakesperiano.

b. ?? Ele fala o inglês shakesperiano BEM.

Tendo em mãos apenas as duas restrições que propusemos até aqui, não é possível fazer a distinção de aceitabilidade correta quanto à distribuição dos advérbios monossilábicos dentro de um VP que tenha como complemento um elemento pesado, como um PP (em (11)) ou um NP pesado (em (12)). Para nosso julgamento, a frase mais natural em (11) é (11a), que respeita ACEnTUeFoco, mas viola AlinheFoco; o mesmo vale para o par em (12).

Contudo, ter um candidato ótimo que viola uma condição mais baixa na hierarquia da língua para respeitar uma condição superior (como (11a) e (12a)) não é nenhum problema para uma análise otimalista. Acontece, porém, que os candidatos (11b) e (12b), os menos favorecidos, não violam nenhuma das duas restrições que propusemos. Em outras palavras, se levarmos em consideração apenas as duas restrições que apresentamos até aqui, os candidatos em (b) deveriam ser os candidatos ótimos em nossas análises, e os candidatos em (a) deveriam ser considerados mal formados. Os dados, no entanto, apontam para outra direção. Acreditamos que, em (11) e (12), existam duas condições de natureza prosódica atuando na distribuição do advérbio. Vejamos quais:

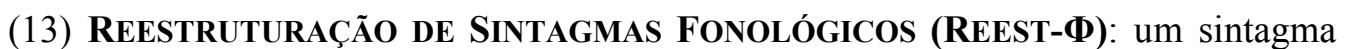
fonológico não-ramificado $\mathrm{Y}$ deve ser integrado ao sintagma fonológico de $\mathrm{X}$ se $\mathrm{Y}$ for o primeiro modificador à direita de $\mathrm{X} .^{18}$

\footnotetext{
${ }^{17}$ Novamente, aqui parece que há dois candidatos completamente aceitáveis em PB, (11a) e (11b), em contraste com os candidatos (11c) e (11d), claramente inadequados ao contexto.

${ }^{18}$ Restrição baseada em Nespor e Vogel (1986) e Menuzzi e Mioto (2006). Na verdade, a formulação em (13) não tem um caráter de "condição de boa-formação sobre uma representação"; antes, parece mais a
} 
A restrição (13) afirma que um sintagma fonológico não-ramificado, como um advérbio monossilábico, deve se unir ao sintagma fonológico do núcleo que está modificando, conquanto o núcleo esteja à sua esquerda. O que queremos dizer é que, seguindo REEST- $\boldsymbol{\Phi}$, a leitura da representação prosódica de (11a) é a seguinte:

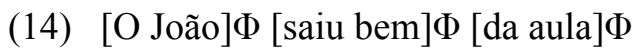

Relacionada à restrição (13), há uma outra condição prosódica atuando:

(15) Complexidade Rítmica Mínima (COMPMin): todo sintagma fonológico deve ser minimamente ramificado (prosodicamente). ${ }^{19}$

A restrição em (15) diz que

[...] [os] sintagmas fonológicos são constituintes da estrutura superior da prosódia da frase; são, em particular, os constituintes a partir dos quais o ritmo da frase se organiza em termos de acentos frasais (secundários e primário, ou nuclear [...]). Obviamente, para haver alternância rítmica entre os acentos frasais de dois sintagmas fonológicos contíguos, é preciso que haja algum material fonológico menos proeminente entre ambos os acentos. [...] [os] sintagmas fonológicos devem ser minimamente constituídos de duas sílabas, e sintagmas fonológicos monossilábicos são desfavorecidos. (MENUZZI; MIOTO, 2006, p. 11-12) (grifos dos autores)

Basicamente, essas duas restrições significam que (i) as línguas, de maneira geral, não favorecem, como sintagmas fonológicos e autônomos, elementos que sejam "leves" (CоMPMin); e (ii) sempre que um elemento leve estiver "solto", ele deve se prender ao núcleo que ele está modificando para formar um sintagma fonológico ramificado

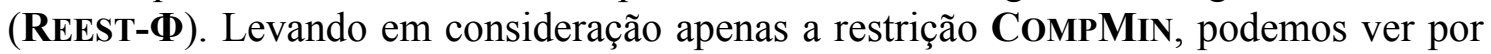
que (11a) é melhor do que (11b). Compare a representação prosódica das duas frases:

(11a) O João saiu BEM da aula.

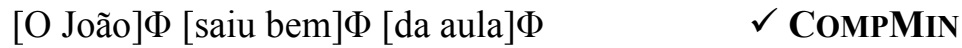

(11b) O João saiu da aula BEM.

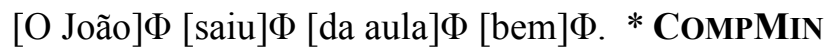

$\mathrm{Na}$ representação prosódica de (11b), o advérbio monossilábico, que não apresenta complexidade rítmica, tem pouca integração prosódica e se vê obrigado a formar um sintagma fonológico por si só, violando a restrição COMPMIN (e também REEST- $\Phi)^{20}$.

definição de uma "operação" sobre elementos linguísticos. Esse é um outro ponto que merece mais atenção no futuro.

19 Restrição proposta por Menuzzi e Mioto (2006, p. 11), mas também baseada nas restrições PARSESYLL (toda sílaba pertence a um pé silábico) e FT-BIN (os pés silábicos são constituídos de duas sílabas), apresentadas em McCarthy e Prince (1994). Princípios como esses são já bem conhecidos em estudos de prosódia; eles seguem linha semelhante ao Princípio de Licenciamento Prosódico, proposto em Itô (1986), de acordo com o qual as unidades prosódicas de um determinado nível devem estar associadas a estruturas prosódicas em níveis superiores. 
Agora, com base nessas quatro restrições, podemos novamente analisar a distribuição dos advérbios monossilábicos dentro do VP:

\begin{tabular}{|c|c|c|c|c|}
\hline & ACENTUEFOCO & COMPMIN & ALINHEFOCO & REEST- $\Phi$ \\
\hline a.Ele saiu BEM da aula & & & $*$ & \\
\hline b.Ele saiu da aula BEM & & $* !$ & & $*$ \\
\hline $\begin{array}{c}\text { c.Ele saiu DA AULA } \\
\text { bem }\end{array}$ & $* !$ & $*$ & & \\
\hline $\begin{array}{c}\text { d.Ele saiu bem DA } \\
\text { AULA }\end{array}$ & $* !$ & & $*$ & \\
\hline
\end{tabular}

TABLEAU 4. Análise de (11): Como é que o João saiu da aula ontem? - Foco no adjunto

O ranking que estamos propondo para o português é o seguinte: ACENTUEFoco $>>$

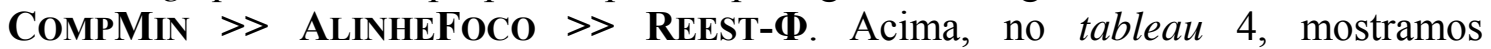
formalmente como essas quatro restrições podem lidar com o fenômeno da distribuição dos advérbios monossilábicos e com a atribuição de acento no VP. O candidato (a), ótimo, viola apenas a restrição ALINHEFoco, para que possa satisfazer outra restrição conflitante e mais alta no ranking, COMPMIN e formar o sintagma fonológico [saiu bem]Ф. O candidato (b) viola duas restrições, justamente as restrições de natureza prosódica, COMPMIN e REEST- $\Phi$, pois apresenta a estruturação prosódica que mostramos em (11b). Os candidatos (c) e (d) violam a restrição mais alta no ranking, ACENTUEFoco e logo são eliminados.

Vejamos a análise das frases (6) e (7), repetidas abaixo, agora com as quatro restrições atuando de forma paralela.

(6) Que língua o João fala bem?
a. O João fala bem INGLÊS.
b. ? O João fala INGLÊS bem.
c. \# O João fala BEM inglês.
d. \# O João fala inglês BEM.

(7) A: O João morou na Austrália por dois anos.

B: Como é que ele fala inglês?

A: a. \# Ele fala bem INGLÊS.

b. \# Ele fala INGLÊS bem.

c. Ele fala BEM inglês.

d. Ele fala inglês BEM.

Antes de passarmos à análise, é necessário que apresentemos também as possibilidades de segmentação prosódica dessas frases: de acordo com Menuzzi e Mioto (2006), o advérbio monossilábico pode se unir ao constituinte verbal, formando os seguintes sintagmas fonológicos:

(16) O João fala inglês BEM.

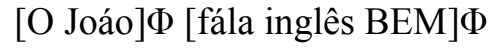

\footnotetext{
${ }^{20} \mathrm{Na}$ verdade, nas análises que apresentamos aqui, todos os candidatos que violam CoMPMIN também violam REEST- $\Phi$. Provavelmente, estamos deixando passar alguma generalização importante aqui. Pretendemos refinar o estudo da atuação dessas duas restrições em trabalhos futuros. Agradecemos a Maria Cristina Figueiredo Silva por nos ter alertado sobre este ponto.
} 
De acordo com esses autores, essa seria a representação preferencial, ao invés de, por exemplo, as representações em (17):

(17a) ? O João fala inglês BEM.

[O Joáo] $\Phi$ [fála inglês] $\Phi[\mathrm{BEM}] \Phi$

(17b) ?? O João fala inglês BEM.

[O Joáo] $\Phi[$ fála] $\Phi$ [inglés $] \Phi[B E M] \Phi$

(17c) \# O João fala inglês BEM.

$[\mathrm{O}$ Joào fála] $\Phi$ [inglès BEM $] \Phi$

A melhor representação, em (16), justifica-se pela aplicação sucessiva de REEST-Ф: o NP leve [inglês] pode ser integrado ao sintagma fonológico do verbo e, então, o advérbio passa a integrar o sintagma fonológico formado por verbo e complemento, formando a estrutura que apresentamos em (16). Veremos, na análise que apresentamos nos tableaux a seguir, que essa intuição parece correta. Além disso, só é possível unir o advérbio ao sintagma fonológico formado por verbo e complemento se, como vimos, o complemento for um NP leve: com o NP pesado que apresentamos em (12) e com um PP como complemento, como vimos em (11), é impossível unir o advérbio ao sintagma fonológico anterior:

(18a) O João fala BEM o inglês que ele aprendeu na escola. $[$ [O João $] \Phi[$ fala bem $] \Phi[$ [o inglês $] \Phi[$ que ele aprendeu $] \Phi[$ na escola $] \Phi$

(18b) ?? O João fala o inglês que ele aprendeu na escola BEM.

$[$ O João] $\Phi[$ fala] $\Phi$ [o inglês $] \Phi[$ que ele aprendeu $] \Phi[$ na escola $] \Phi[$ bem $] \Phi$

Seguindo essa mesma linha de raciocínio, podemos chegar ainda a uma outra conclusão: podemos também prever que um advérbio "pesado" não necessita se unir ao sintagma fonológico formado por verbo e complemento. O julgamento de aceitabilidade de (19) parece comprovar isso:

(19) A: O João morou na Austrália por dois anos.

B: Como é que ele fala inglês?

A: a. O João fala inglês PERFEITAMENTE.

[O João] $\Phi$ [fala inglês] $\Phi$ [perfeitamente] $\Phi$

b. ? O João fala PERFEITAMENTE inglês.

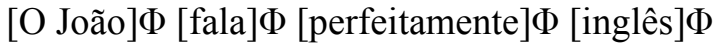

Vejamos as análises dessas frases nos tableaux seguintes, a começar pelas frases (6) e $(7)^{21}$ :

\footnotetext{
${ }^{21}$ Para não sobrecarregar a leitura dos tableaux 5 e 6, entenda-se que a segmentação prosódica dos candidatos a output são aquelas que apresentamos em (16), ou seja, com o advérbio formando um sintagma fonológico juntamente com o verbo e com o complemento: [fala inglês bem] $\Phi$. Nenhum dos candidatos vai violar, portanto, as restrições COMPMIN e REEST- $\Phi$.
} 


\begin{tabular}{|c|c|c|c|c|}
\hline & ACENTUEFOCO & COMPMIN & ALINHEFOCO & REEST- $\Phi$ \\
\hline a. Ele fala bem INGLÊS & & & & \\
\hline b. Ele fala INGLÊS bem & & & $* !$ & \\
\hline c. Ele fala BEM inglês & $* !$ & & & \\
\hline d. Ele fala inglês BEM & $* !$ & & $*$ & \\
\hline
\end{tabular}

TABLEAU 5. Reanálise das frases em (6): Que língua o João fala bem? - Foco no complemento

\begin{tabular}{|c|c|c|c|c|}
\hline & ACENTUEFOCO & COMPMIN & ALINHEFOCO & REEST- $\Phi$ \\
\hline a. Ele fala bem INGLÊS & $* !$ & & $*$ & \\
\hline b. Ele fala INGLÊS bem & $* !$ & & & \\
\hline c. Ele fala BEM inglês & & & $* !$ & \\
\hline d. Ele fala inglês BEM & & & & \\
\hline
\end{tabular}

TABLEAU 6: Reanálise das frases em (7): Como é que o João fala inglês? - Foco no adjunto

Se nossas restrições estiverem adequadas e a organização do ranking estiver correta, poderemos explicar ainda mais um fato concernente ao comportamento da ordenação de elementos dentro do VP. Podemos explicar formalmente por que os elementos leves, de maneira geral, preferem ficar próximos ao núcleo, como nos VPs com um NP pesado seguido de advérbio monossilábico ou com advérbios fonologicamente complexos que são modificadores de VPs com objetos "leves", como mostramos em (19). Vejamos as análises nos tableaux abaixo:

\begin{tabular}{|c|c|c|c|c|}
\hline & ACENTUEFOCO & COMPMIN & ALINHEFOCO & REEST- $\Phi$ \\
\hline $\begin{array}{c}\text { a. Ele fala BEM o inglês } \\
\text { shakespeariano }\end{array}$ & & & $*$ & \\
\hline $\begin{array}{c}\text { b. Ele fala o } \\
\text { shakespeariano BEM }\end{array}$ & & $* !$ & & $*$ \\
\hline
\end{tabular}

TABLEAU 7. Análise das frases em (12): Como o João fala inglês? - Foco no adjunto

\begin{tabular}{|l|l|l|c|c|}
\hline & ACENTUEFOCO & COMPMIN & ALINHEFOCO & REEST- $\Phi$ \\
\hline $\begin{array}{l}\text { a. Ele fala inglês } \\
\text { PERFEITAMENTE }\end{array}$ & & & & \\
\hline $\begin{array}{l}\text { b. Ele fala } \\
\text { PERFEITAMENTE } \\
\text { inglês }\end{array}$ & & & $* !$ & \\
\hline
\end{tabular}

TABLEAU 8. Análise das frases em (19): Como é que o João fala inglês? - Foco no adjunto

Nos tableaux 7 e 8, vemos que a hierarquia proposta parece correta e, mais do que isso, as restrições que propusemos podem explicar não só o comportamento dos advérbios monossilábicos dentro do VP, mas também a distribuição de elementos leves e pesados, de maneira geral, dentro do VP. Pudemos fazer isso sem precisar dispor de nenhum mecanismo estritamente sintático que fosse "cego" frente a necessidades fonológicas, prosódicas ou de estrutura informacional da língua. Além disso, também explicamos corretamente por que frases como (6a), (7d) e (19a) são consideradas não-marcadas na língua: elas obedecem às restrições propostas, sem necessidade de violá-las. E em não 
violando nenhuma restrição, não há, como enfatiza Smolensky (1993), literalmente, nenhuma marca(ção) referente às restrições em questão na gramática da língua.

\section{CONSIDERAÇÕES FINAIS}

Partimos de um ponto que julgamos problemático na análise de Costa (1998), a saber: em seu trabalho, Costa utiliza a Teoria da Otimidade, mas, ainda assim, sobrecarrega o componente sintático para explicar um fenômeno que, aparentemente, obedece a outras exigências que não exigências sintáticas. Nosso trabalhou tentou mostrar que algumas explicações concebidas como exclusivamente sintáticas merecem ser revistas se levarmos em consideração que não há necessidade de os fatores sintáticos terem primazia sobre outros componentes da gramática que estejam atuando na organização dos constituintes na frase. Mais especificamente, apresentamos uma análise em TO que mostrou como restrições de natureza prosódica e de estrutura informacional da frase estão atuando sobre a distribuição dos elementos dentro do VP em português; ou seja, a ordem dos constituintes do VP em português brasileiro parece resultar da interação de condições prosódicas e de articulação informacional.

A partir da análise que apresentamos aqui, pretendemos ainda investigar como simplificar a estrutura sintagmática abstrata da frase. Acreditamos que exista uma restrição de natureza sintática que também pode estar atuando, mais ou menos no teor de ECONOMY ou STAY, condições que dizem algo como "mantenha a ordem sintática básica das sentenças da língua" ${ }^{22}$. Também desconfiamos, como mencionamos anteriormente, que uma análise da estrutura sintagmática tal como propõem Culicover e Jackendoff (2003) possa ser interessante. Em Sintaxe TO, é comumente postulado que o input obedece aos princípios básicos da teoria X-barra ${ }^{23}$ (binaridade, endocentricidade, nuclearidade etc.). No entanto, pretendemos investigar a possibilidade de esses princípios serem, na verdade, condições que podem ser violadas, estando presentes em CON. Para isso, devemos revisitar os princípios básicos da Teoria X-barra (CHOMSKY, 1970; JACKENDOFF, 1977; STOWELL, 1981; KORNAI e PULLUM, 1990) e verificar se podemos codificar os princípios configuracionais da X-barra como restrições gramaticais universais - de natureza violável, como preditos pela TO.

Finalmente, outro passo que deveremos dar é efetuar uma análise tipológica, pesquisando em outras línguas como se dá a distribuição de elementos leves e a atribuição de acento nuclear na frase. Teremos de pôr à prova nossas restrições e verificar o ranqueamento de outras línguas. Além disso, ao longo do texto, mostramos diversos pontos de nossa análise que ainda não consideramos ideais; pretendemos revistá-los em nossos próximos trabalhos.

\footnotetext{
${ }^{22}$ Cf. restrições dessa natureza em Grimshaw (1997), Choi (1997, 1999), Legendre, Smolensky e Wilson (1998), Costa (2001b), Menuzzi e Othero (2008).

${ }^{23}$ Cf. Legendre (2001), Kuhn (2003).
} 


\section{REFERÊNCIAS}

ABAURRE, M. B.; GALVES, C.; MANDEL, A.; SANDALO, F. The Sotaq optimality based computer program and secondary stress in two varieties of Portuguese. Rutgers Optimality Archive, ROA, 2001.

ABAURRE, M. B.; SANDALO, F. Acento secundário em duas variedades de português: uma análise baseada na OT. In: ARAUJO, G. A. (Org.) O acento em português. São Paulo: Parábola Editorial, 2007.

ARCHANGELI, D. Optimality Theory: an introduction to Linguistics in the 1990s. In: ARCHANGELI, D.; LANGENDOEN, D. T. (Eds.) Optimality Theory: an overview. Oxford: Blackwell, 1997.

BARBOSA, P. et al. (Eds.) Is the best good enough? Optimality and competition in syntax. Cambridge: MIT Press, 1998.

BISOL, L. Os constituintes prosódicos. In: BISOL, L. (Org.) Introdução a estudos de fonologia do português brasileiro 4. ed. Porto Alegre: EDIPUCRS, 2005.

; MAGALHÃES, J. S. A redução vocálica no português brasileiro: avaliação via restrições. Revista da Abralin, v. III, 2005.

BONILHA, G. Brazilian Portuguese syllabic structure acquisition: an analysis of the falling oral diphthongs. Rutgers Optimality Archive, ROA, 2001.

- Aquisição dos ditongos orais decrescentes: contribuições da Teoria da Otimidade. Letras de Hoje, v. 42, 2007.

BRESNAN, J. Optimal syntax: notes on projection, heads, and optimality. Stanford University, 1996.

BÜRING, D. Semantics, intonation and information structure. In: RAMCHAND, G.; REISS, C. (Eds.) The Oxford handbook of linguistic interfaces. OUP, Oxford, 2007.

BURY, D. Phrase structure and derived heads. University College London, Tese de Doutorado, 2003.

BYRNE, F.; WINFORD, D. (Eds.) Focus and grammatical relations in Creole languages. Amsterdam: John Benjamins, 1993.

CHOI, H-W. Information structure, phrase structure, and their interface. Proceedings of the LFG97 Conference. University of San Diego, 1997.

Optimizing structure in context: scrambling and information structure. CSLI Publications, 1999. 
CHOMSKY, N. Remarks on nominalization. In: JACOBS, R.; ROSENBAUM, P. (Eds.) English Transformational Grammar. Washington: Georgetown University Press, 1970.

CINQUE, G. A null theory of phrase and compound stress. Linguistic Inquiry, 24, 1993.

COSTA, J. Word order and constraint interaction. Rutgers Optimality Research Grant, Rutgers University, 1996a.

Optimality Theory at the Syntax-Discourse Interface: a case study of word order. Linguistics Colloquium, University of Groningen, 1996b. $1996 \mathrm{c}$

Word-order and Optimality theory. Staff seminar, University of Tilburg,

Word order variation - a constraint-based approach. The Hague: Holland Academic Graphics, 1998.

. Gramática, conflitos e violações: introdução à Teoria da Optimidade. Editorial Caminho, Lisboa, 2001a.

The emergence of unmarked word order. In: LEGENDRE, G.; GRIMSHAW, J.; VIKNER, S. (Eds.) Optimality-theoretic syntax. Cambridge: MIT Press, $2001 \mathrm{~b}$.

Marked vs. Unmarked inversion in Optimality Theory. In: HULK, A.; POLLOCK, J-Y. (orgs.) Inversion in romance. New York: Oxford University Press, 2001c.

CULICOVER, P. W.; JACKENDOFF, R. Simpler syntax. Oxford $\backslash$ New York: Oxford University Press, 2005.

DERBYSHIRE, D. Hixkaryana and linguistic typology. Arlington: SIL, 1985.

de HOOP, H. Case configuration and noun phrase interpretation. University of Groningen, Tese de Doutorado, 1992.

DRESHER, E. The rise of Optimality Theory in first century Palestine. GLOT International 2, 1/2, 1996.

ENGELS, E. Adverb placement. An optimality theoretic approach. Potsdam, Tese de Doutorado, 2004.

ERTESCHIK-SHIR, N. Information structure: the syntax-discourse interface. Oxford: OUP, 2007.

; LAPPIN, S. Under stress: a functional explanation of sentence stress. Journal of Linguistics 19, 1993. 
FIGUEIREDO SILVA, M. C.; ARAÚJO, F. M. Prosódia e ordem das palavras: o caso dos advérbios ditos monossilábicos átonos. ReVEL, vol. 6, n. 10, 2008.

FROTA, S. Prosody and focus in European Portuguese: phonological phrasing and intonation. New York: Garland, 2000.

FUKAYA, N. Optimality Theory and word order change in English. 19th Annual Conference of the English Linguistic Society of Japan, 2002.

GIVÓN, T. Mind, code and context: essays in Pragmatics. Hillsdale: Lawrence Erlbaum Associates, 1989.

GOLSTON, Chris. Syntax outranks phonology. Phonology, 12, 1995.

GRIMSHAW, J. Projections, heads, and optimality. Linguistics Inquiry 28(3), 1997.

; SAMEK-LODOVICI, V. Optimal subjects. In: BECKMAN, J. et al. (Eds.) University of Massachusetts occasional papers 18: papers in Optimality Theory. GSLA, University of Massachusetts, Amherst, 1995.

; SAMEK-LODOVICI, V. Optimal subjects and subject universals. In: BARBOSA, P. et al. (Eds.) Is the best good enough? Optimality and competition in syntax. Cambridge: MIT Press, 1998.

HARFORD, C.; DEMUTH, K. Prosody outranks syntax: an optimality approach to subject inversion in Bantu relatives. Linguistic Analysis, 29 (1-2), 1999.

ITÔ, J. Syllable theory in Prosodic Phonology. University of Massachusetts, Tese de Doutorado, 1986.

JACKENDOFF, R. Semantic interpretation in Generative Grammar. Cambridge: MIT Press, 1972.

X' syntax: a study of phrase structure. Cambridge: MIT Press, 1977.

KELlER, F.; ALEXOPOUlOU, T. 2001. Phonology competes with syntax: experimental evidence for the interaction of word order and accent placement in the realization of information structure. Cognition, 79 (3), 2001.

KISS, K. (Ed.) Discourse configurational languages. Oxford: Oxford University Press, 1995.

KOCH, K. A. Focus projection in Nlaka'pamux (Thompson River Salish). Proceedings of the 26th West Coast Conference, 2008.

KORNAI, A.; PULlUM, G. K. The X-bar theory of phrase structure. Language, 66, 1990. 
KUHN, J. Optimality-theoretic syntax - a declarative approach. CSLI Publications, 2003.

LEE, S. H. O acento primário no português: uma análise unificada na teoria da otimalidade. In: ARAUJO, G. A. (Org.) O acento em português. São Paulo: Parábola Editorial, 2007.

LEGENDRE, G. An introduction to optimality theory in syntax. In: LEGENDRE, G.; GRIMSHAW, J.; VIKNER, S. (eds.) Optimality-Theoretic Syntax. MIT Press, 2001.

; GRIMSHAW, J.; VIKNER, S. (Eds.) Optimality - theoretic syntax. Cambridge: MIT Press, 2001.

; SMOLENSKY, P.; WILSON, C. When is less more? Faithfulness and minimal links in wh-chains. In: BARBOSA, P. et al. (Eds.) Is the best good enough? Optimality and competition in syntax. Cambridge: MIT Press, 1998.

McCARTHY, J. A thematic guide to Optimality Theory. Cambridge: Cambridge University Press, 2002.

; PRINCE, A. Prosodic Morphology I: constraint interaction and satisfaction. Manuscrito, University of Massachusetts, Amherst, and Rutgers University, New Brunswick, N. J., 1993.

; PRINCE, A. The emergence of the unmarked: optimality in Prosodic Morphology. Proceedings of the North East Linguistic Society 24. Amherst: GLSA Publications, 1994.

MENUZZI, S. Binding Theory and pronominal anaphora in Brazilian Portuguese. The Hague: Holland Academic Graphics, 1999.

; MIOTO, C. Advérbios monossilábicos pós-verbais no PB: sobre a relação entre sintaxe e prosódia. Revista de Estudos da Linguagem, v. 14, n. 2, 2006.

; OTHERO, G. A. Functional constraints on Wh-question formation. Rutgers Optimality Archive, ROA, 2008.

MIYAGAWA, S. Against optional scrambling. Linguistic Inquiry 28(1), 1997.

NESPOR, M.; VOGEL, I. Prosodic Phonology. Dordrecht: Foris, 1986.

OTHERO, G. A. Isaac Asimov e a Teoria da Otimidade. Linguagem - Revista Eletrônica de Popularização Científica em Ciências da Linguagem, v. 6, 2009.

PRINCE, A.; SMOLENSKY, P. Optimality Theory: constraint interaction in Generative Grammar. RuCCs Technical Report 2, Rutgers University Center for Cognitive Science, Piscataway, N. J., 1993. 
REINHART, T. Focus - The PF Interface. In: REINHART, T. Interface strategies: Reference Set Computation. Cambridge: MIT Press, 2003.

SAMEK-LODOVICI, V. Prosody-Syntax interaction in the expression of focus. Natural language and linguistic theory, Dordrecht, v. 23, 2005.

SANDALO, F.; TRUCKENBRODT, H. Some notes on phonological phrasing in Brazilian Portuguese. D.E.L.T.A., vol. 19, n. 1, 2003.

SCHWINDT, L. C. Teoria da Otimidade e fonologia. In: BISOL, L. (Org.) Introdução a estudos de fonologia do português brasileiro. 4. ed. Porto Alegre: EDIPUCRS, 2005 .

- Paradigmatic correspondences in the Brazilian Portuguese verbal vowel system. Journal Acta Linguistica Hungarica, vol. 54, n. 4, 2007.

SELKIRK, E. Phonology and syntax: the relation between sound and structure. Cambridge: MIT Press, 1984.

Sentence prosody: intonation, stress, and phrasing. In: GOLDSMITH, J. A. (Ed.) The handbook of phonological theory. London: Basil Blackwell, 1995.

SELLS, P. (ed.) Formal and empirical issues in optimality theoretic syntax. Stanford: CSLI Publications, 2001.

SMOLENSKY, P. Harmony, markedness, and phonological activity. Handout. Rutgers Optimality Archive, ROA, 1993.

STOWELL, T. Origins of phrase structure. Massachusetts, MIT, Tese de Doutorado, 1981.

TEEPLE, David. Prosody Can Outrank Syntax. Proceedings of the 26th West Coast Conference on Formal Linguistics, 2008.

TRUCKENBRODT, H. The Syntax-Phonology Interface. In: DE LACY, P. (Org.) The Cambridge handbook of phonology. Cambridge: Cambridge University Press, 2005. 